\title{
Urinary excretion of hydroxyproline in workers occupationally exposed to vibration
}

\author{
T KASAMATSU, K MIYASHITA, S SHIOMI, AND H IWATA \\ From the Department of Public Health, Wakayama Medical College, Wakayama, 640, Japan
}

\begin{abstract}
Urinary hydroxyproline excretion was measured in 130 chain saw operators aged 28-59 and in 31 normal control subjects aged 26-59 with no occupational exposure to vibration. The results measured were expressed as a ratio of hydroxyproline to creatinine. (1) No significant correlation between hydroxyproline/creatinine ratio and age was observed among normal subjects. (2) In chain saw operators grip and pinch strength decreased gradually with an increase of the total chain saw operating time, while the prevalence of pain in the hands or motility disturbance in the elbow joints showed a tendency to become greater as total operating time increased. Hydroxyproline/ creatinine ratio in the group with over 9000 hours' experience was significantly higher than that in the group with under 3000 hours $(p<0.05)$. By comparison with controls, the ratio in the group with over 3000 hours was significantly higher at the $5 \%$ level. (3) Hydroxyproline/creatinine ratio in the group with pain in the hands or with motility disturbance in the elbow joints was significantly higher than that in the group without them $(p<0.05)$. (4) Hydroxyproline/creatinine ratio was inversely correlated with grip and pinch strength in operators ranging in age from 40 to 49 ( $p<0 \cdot 01)$. (5) All individual ratios for operators with lower grip strength showed a higher increment than the mean values obtained from controls. These results indicate that increased urinary hydroxyproline excretion in chain saw operators may occur in association with damage to the musculoskeletal system caused by the prolonged use of vibrating tools.
\end{abstract}

It has been well recognised that long-term or repeated hand-arm vibration often causes various lesions to workers using vibrating tools. These include damage to the musculoskeletal system including changes in the muscles, bones, and joints of the hands. ${ }^{1}$ This damage is important because it shows continuous organic changes caused by the prolonged use of heavy vibrating tools. Several examinations, such as radiography, electromyography, motility of movement, and grip and pinch strength, have been used to diagnose the damage to the musculoskeletal system. ${ }^{2-5}$ These tests, however, are not always effective in precisely diagnosing such symptoms.

High levels of urinary hydroxyproline excretion occur in various pathological conditions such as skeletal or connective tissue disorders. ${ }^{6-8}$ It is currently considered that estimations of urinary hydroxyproline can be used as an index of the daily turnover of collagen in the human organism because hydroxyproline is found almost exclusively in

Received 27 July 1981

Accepted 14 August 1981 collagen. ${ }^{7}$ Moreover, increased urinary excretion of this substance in people exposed to vibration has been reported. ${ }^{9}$

The present study was therefore undertaken to investigate the relationship of urinary hydroxyproline excretion to subjective symptoms or clinical signs of muscles and joints, or muscular strength in workers exposed to local vibration.

\section{Materials and methods}

SUBJECTS

For this study 130 chain saw operators aged from 28 to 59 (average age, 45.2), and 31 normal healthy subjects aged from 26 to 59 (average age, 39.1) with no occupational exposure to vibration participated (table 1).

\section{CHAIN SAW OPERATING TIME}

To determine the vibration exposure dose for an individual the total operating time using a chain saw (TOT) was calculated from the full occupational history by using the following equation: chain saw 
Table 1 Age of the subjects

\begin{tabular}{lllrr}
\hline \multicolumn{5}{c}{ Age $(y r)$} \\
\cline { 2 - 5 } & $20-29$ & $30-39$ & $40-49$ & $50-59$ \\
\hline No $(\%)$ of controls & $7(22 \cdot 6)$ & $10(32 \cdot 3)$ & $6(19 \cdot 3)$ & $8(25 \cdot 8)$ \\
No $(\%)$ of operators & $2(1 \cdot 5)$ & $13(10 \cdot 0)$ & $65(50 \cdot 0)$ & $50(38 \cdot 5)$ \\
\hline
\end{tabular}

operating hours/day $\times$ days/year $\times$ years.

All chain saw operators were classified into four groups according to TOT. The groups were as follows: $32(24 \cdot 6)$ operators with up to 3000 hours' experience, $30(23 \cdot 1)$ with $3000-6000$ hours' experience, $25(19 \cdot 2)$ with 6000-9000 hours' experience, and $43(33 \cdot 1)$ with over 9000 hours' experience.

\section{COLLECTION OF URINARY SAMPLES}

All subjects were instructed to take a gelatin-free diet at least one day before the collection of urine. The spot urine samples were collected from 0900 to 1100 , put into polyethylene bottles containing toluene as a preservative, and stored at $-20^{\circ} \mathrm{C}$ until required. Urinary total hydroxyproline-that is, free plus peptide hydroxyproline-was measured by a modification of the method of Parekh and Jung ${ }^{10}$ using one portion of the sample after acid hydrolysis in an autoclave at $124^{\circ} \mathrm{C}$ for two hours. In addition, urinary creatinine was determined using another portion of the specimen by the alkaline picrate method. ${ }^{11}$ The results of hydroxyproline excretion in urine are expressed as a ratio of micrograms hydroxyproline to milligrams creatinine.

\section{MUSCULAR STRENGTH}

The muscular strength of hand-grip and pinch in both hands was measured by using the hand-grip dynamometer and pinch meter of a strain-gauge, respectively. The subjects were given five opportunities with each hand to exert their most forceful grip, and the highest of the ten measurements was adopted as their grip strength. The subjects were then given two opportunities to exert maximum force grasping a strain-gauge between pads of thumb and index finger of each hand, and the highest value of either side was adopted as their pinch strength. Measurements in these two tests were expressed in units of kilograms of force.

\section{SUBJECTIVE SYMPTOMS}

Chain saw operators were divided into two groups according to the existence or non-existence of subjective symptoms, including pain in the hands associated with using hand-held vibrating tools: 78 operators were without pain and 52 had pain.

\section{CLINICAL SIGNS}

The same operators mentioned above were further divided into two groups in accordance with clinical signs testing the motility of the elbow joints-that is, restriction of flexion and extention: 92 operators were without motility disturbance and 38 had motility disturbance.

\section{STATISTICAL METHODS}

The data were analysed by Student's $t$-test and by linear regression analysis.

\section{Results}

HYDROXYPROLINE/CREATININE RATIO IN RELATION TO AGE

The correlation between urinary hydroxyproline/ creatinine ratio and age was determined in a group of control subjects aged from 26 to 59 . No statistically significant correlation was observed (fig 1).

CHANGES IN MUSCULAR STRENGTH, PREVALENCE OF SYMPTOMS AND SIGNS, AND HYDROXYPROLINE/CREATININE RATIO RELATED TO TOT

The grip and pinch strength decreased gradually with an increase in TOT (table 2). By contrast, the prevalence of pain in the hands and motility disturbance in the elbow joints showed a tendency to increase with increasing TOT. Urinary hydroxyproline/creatinine ratio was significantly higher in the group with over 9000 hours' experience than in the group with under 3000 hours' experience $(\mathrm{p}<0.05)$; however, by comparison with controls, the ratios in all chain saw operating groups with

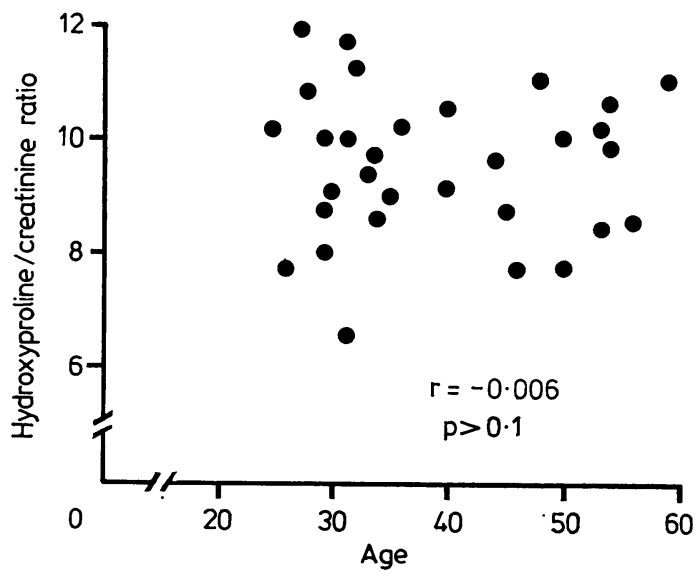

Fig 1 Relationship between urinary hydroxyproline/ creatinine ratio and age in control subjects. 
Table 2 Changes in muscular strength, prevalence of pain or motility disturbance, and urinary hydroxyproline/ creatinine ratio according to TOT

\begin{tabular}{clllrrr}
\hline TOT (hours) & No & Grip strength $(\mathrm{Kg})$ & Pinch strength $(\mathrm{Kg})$ & Pain & Motility disturbance & Hydroxyproline/creatinine ratio \\
\hline$<3000$ & 32 & $45 \cdot 2 \pm 5 \cdot 9$ & $6 \cdot 1 \pm 1 \cdot 8$ & $9(28 \cdot 1)$ & $8(25 \cdot 0)$ & $10 \cdot 6 \pm 3 \cdot 8$ \\
$3000-6000$ & 30 & $43 \cdot 9 \pm 7 \cdot 7$ & $6 \cdot 0 \pm 1 \cdot 9$ & $10(33 \cdot 3)$ & $5(16 \cdot 7)$ & $11 \cdot 9 \pm 3 \cdot 5 *$ \\
$6000-9000$ & 25 & $41 \cdot 5 \pm 7 \cdot 6$ & $5 \cdot 4 \pm 2 \cdot 1$ & $12(48 \cdot 0)$ & $8(32 \cdot 0)$ & $11 \cdot 3 \pm 4 \cdot 4^{*}$ \\
$>9000$ & 43 & $40 \cdot 8 \pm 7 \cdot 8$ & $5 \cdot 3 \pm 1 \cdot 9$ & $21(48 \cdot 8)$ & $17(39 \cdot 5)$ & $12 \cdot 6 \pm 4 \cdot 3 * *+$ \\
Controls & 31 & & & & $9 \cdot 5 \pm 1 \cdot 3$ \\
\hline
\end{tabular}

Figures are mean \pm SD. Figures in parentheses represent the percentage of each TOT group.

${ }^{*} \mathrm{p}<0.05,{ }^{* *} \mathrm{p}<0.01$, as compared with controls.

tp $<0.05$, as compared with the group having under 3000 hours' experience.

Table 3 Comparison of urinary hydroxyproline/ creatinine ratio between groups with and without pain, and between groups with and without motility disturbance

\begin{tabular}{lll}
\hline Symptoms and signs & No & $\begin{array}{l}\text { Hydroxyproline/creatinine } \\
\text { ratio }\end{array}$ \\
\hline Pain negative & 78 & $10 \cdot 9 \pm 2 \cdot 9$ \\
Pain positive & 52 & $12 \cdot 4 \pm 4 \cdot 1^{*}$ \\
Motility disturbance negative & 92 & $10 \cdot 9 \pm 3 \cdot 1$ \\
Motility disturbance positive & 38 & $12 \cdot 2 \pm 3 \cdot 8^{*}$ \\
\hline
\end{tabular}

Figures are mean \pm SD.

${ }^{*} p<0.05$, as compared with the group without pain or motility disturbance, respectively.

more than 3000 hours' experience were significantly increased at the $5 \%$ level.

\section{HYDROXYPROLINE/CREATININE RATIO}

RELATED TO SYMPTOMS AND SIGNS

Urinary hydroxyproline/creatinine ratios between groups with or without pain in the hands, also between groups with or without motility disturbance in the elbow joints were compared (table 3). Hydroxyproline/creatinine ratio in the group with pain or with motility disturbance was significantly higher than in the group without either $(p<0.05)$.

\section{CORRELATION BETWEEN HYDROXYPROLINE/ \\ CREATININE RATIO AND MUSCULAR STRENGTH}

It is evident from previous studies that muscular strength is affected by age. ${ }^{12}$ To investigate the relationship between the urinary hydroxyproline/ creatinine ratio and muscular strength, excluding the age factor, 65 of the 130 chain saw operators, aged from 40 to 49 , were selected. The relationships between hydroxyproline/creatinine ratio and grip strength, and between hydroxyproline/creatinine ratio and pinch strength are shown in figs 2 and 3 , respectively. Urinary hydroxyproline/creatinine ratio was inversely correlated with grip strength $(\mathrm{r}=$ $-0.396, \mathrm{p}<0.01)$ and pinch strength $(\mathrm{r}=-0.369$, $\mathrm{p}<0.01)$.

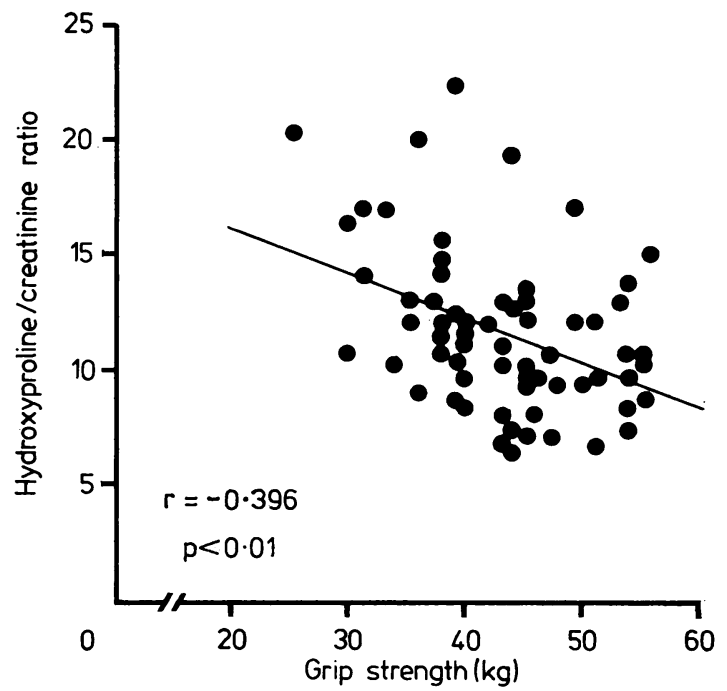

Fig 2 Relationship between urinary hydroxyproline/ creatinine ratio and grip strength in chain saw operators aged 40-49 years.

HYDROXYPROLINE/CREATININE RATIO IN CHAIN SAW OPERATORS WITH LOWER GRIP STRENGTH

Of all chain saw operators, five with lower grip strength of less than $30 \mathrm{~kg}$ were sampled. The distribution of urinary hydroxyproline/creatinine ratios in control subjects and the five chain saw operators with lower grip strength are illustrated in fig 4. Overall, the individual ratios for controls tended to cluster around their mean values. All individual ratios for operators showed a higher increment than the mean values obtained from controls.

\section{Discussion}

Since hydroxyproline is found almost entirely in collagen, its excretion in the urine is related to the 


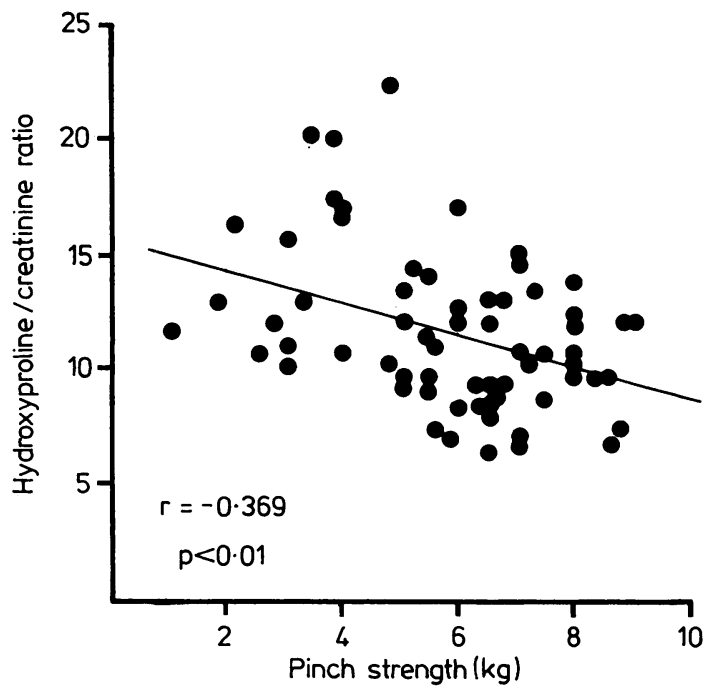

Fig 3 Relationship between urinary hydroxyproline/ creatinine ratio and pinch strength in chain saw operators aged 40-49 years.

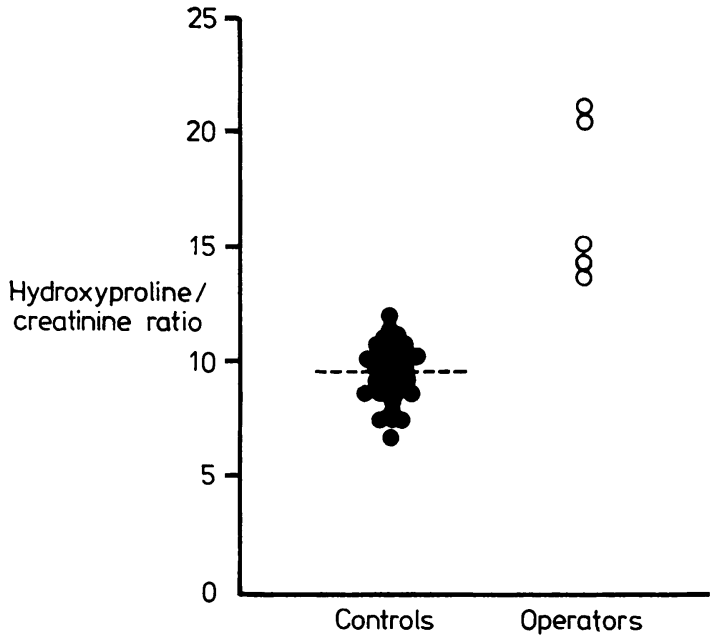

Fig 4 Distribution of urinary hydroxyproline/ creatinine ratio in control subjects $(O)$ and in chain saw operators with lower grip strength $(\bigcirc)$. Broken line represents mean values obtained from control subjects.

rate of collagen turnover. ${ }^{7}$ It is thought that urinary hydroxyproline excretion is raised not only by endogenous but also by dietary factors. Of dietary constituents, only gelatin is believed to contribute to increased hydroxyproline excretion in urine. ${ }^{13}$ Thus all the subjects were instructed to take a gelatin-free diet but not to restrict the intake of meat and related products, because it is believed that meat intake influences urinary hydroxyproline excretion only slightly. ${ }^{14}$

When determining the concentration of urinary constituents it is desirable that all urine samples in a 24-hour period should be carefully collected. Nevertheless, it is actually difficult to collect them except in special cases-for instance, inpatients in a hospital or people who stay at home all day. In the present study, therefore, spot urine samples were collected and hydroxyproline excretion in urine was expressed as a ratio of hydroxyproline to creatinine. Howells et al $^{15}$ observed that the hydroxyproline/ creatinine ratios derived from 24-hour samples and from random samples were closely correlated $(r=0.98)$; Younoszai et al ${ }^{16}$ report the same results. Allison et al ${ }^{17}$ suggest that the ratio of hydroxyproline/creatinine may have a greater usefulness in evaluating urinary hydroxyproline excretion than 24-hour urinary hydroxyproline value only. Thus the collection of single samples instead of 24-hour specimens seems to provide a reasonable estimate of urinary hydroxyproline excretion.

As urinary hydroxyproline varies considerably with age $^{7}$ we investigated the relationship between urinary hydroxyproline/creatinine ratio and age in normal subjects aged from 26 to 59 . Our findings are similar to the results obtained by Allison et al, ${ }^{17}$ who indicated that urinary hydroxyproline/creatinine ratio varies with the acceleration of growth but remains constant during the ages from 20 to 70 in normal people.

On the other hand, to estimate the vibration exposure dose due to vibrating tools, the number of years the tools were used has been generally applied. ${ }^{18}{ }^{19}$ In the case of forestry workers, however, the number of hours a day or the number of days a year, or both, that they operated a chain saw varied considerably from individual to individual. Therefore, TOT was used as a parameter for assessing vibrating exposure dose for any one individual. In connection with this TOT there seems to exist a moderate dose-response relationship of TOT to muscular strength, prevalence of pain in the hands or motility disturbance in the elbow joints, and hydroxyproline/creatinine ratio as shown in table 2 . We have confirmed our previous observation ${ }^{20}$ that grip and pinch strength gradually decreased with an increase in TOT, while prevalence of pain in the hands increased with an increase in TOT.

Long-term use of hand-held vibrating tools tends to cause damage to the musculoskeletal system in the hands. This damage occurs especially among workers who operate relatively heavy vibrating tools or do heavy work in a strained posture. Milano et $a l^{21}$ reviewed the mechanism of vibration 
transmission, in which they made clear that losses of vibratory energy occurred between the hand and elbow, while still further losses of energy occurred between the elbow and shoulder, most of which were absorbed at the joints.

Available data have indicated that the disturbance due to vibration includes subjective symptoms such as paraesthesia, numbness and pain, and clinical signs such as weakness of muscular strength and changes in muscles, bones, and joints. ${ }^{522} 23$ Of these, damage to the elbow joints and pain in the hands are comparatively frequent. Pain seems to be a secondary occurrence associated with the damage to the muscles and joints. To quantify the structural changes in skeleton, $x$-ray findings have been commonly used, but we, unfortunately, had no opportunities to conduct $x$-ray examinations. Many studies concerning the prevalence of typical osteoarticular lesions such as bone cysts, osteoarthritis, osteoporosis, and elbow exostosis in workers exposed to local vibration have been reported. ${ }^{22-26}$

In the present study we directed our attention to the pain in the hands and the damage to the elbow joints, and investigated the relationship between urinary hydroxyproline/creatinine ratio and these symptoms and signs. As can be seen in table 3, hydroxyproline/creatinine ratio in chain saw operators with pain in the hands or with motility disturbance in the elbow joints was significantly higher than that in operators without them.

On the other hand, muscular strength, like grip strength, has been used to determine the seriousness of injuries in the hands. ${ }^{27}$ Chain saw operators with pain in the arms or with disturbance in the elbow joints may tend to have decreased muscular strength. Actually, Iwata ${ }^{24}$ reported that vibrating tool operators, with deformity in the elbow that appeared in $x$-ray findings, showed a remarkable decrease in their grip strength. As muscular strength is affected by age, the relationship between urinary hydroxyproline/creatinine ratio and muscular strength was examined in chain saw operators aged from 40 to 49 . Hydroxyproline/creatinine ratio was inversely correlated with the muscular strength, although age effect on muscular strength was controlled. In other words, the lower the muscular strength becomes, the higher the hydroxyproline/creatinine ratio rises. Further evidence was observed that all individual ratios of hydroxyproline to creatinine in chain saw operators with lower grip strength were higher than the mean values obtained from control subjects.

Recently, increased excretion of urinary hydroxyproline in individuals exposed to local vibration was observed by Sroczyński et al, ${ }^{9}$ who assumed such changes were caused by damage to the collagen fibres.
From the combined findings mentioned above, we presume that to repair alterations to muscles and bones caused by prolonged use of vibrating tools, the synthesis of new collagen is accelerated, since it produces increased hydroxyproline excretion in urine as a necessary consequence. In conclusion, the present study suggests that urinary hydroxyproline excretion may be used as an indicator of the damage to the musculoskeletal system caused by prolonged use of hand-held vibrating tools.

\section{References}

1 Taylor W, Pearson J, Kell RL, Keighley GD. Vibration syndrome in Forestry Commission chain saw operators. Br J Ind Med 1971;28:83-9.

${ }^{2}$ Kumlin T, Wiikeri M, Sumari P. Radiological changes in carpal and metacarpal bones and phalanges caused by chain saw vibration. Br J Ind Med 1973;30:71-3.

${ }^{3}$ Sakurai T. Vibration effects on hand-arm-system (part 1). Observation of electromyogram. Ind Health 1977;15: 47-58.

${ }^{4}$ Färkkilä M, Pyykkö I, Korhonen O, Starck J. Vibrationinduced decrease in the muscle force in lumberjacks. Eur J Appl Physiol 1980;43:1-9.

${ }^{5}$ McCallum RI. Vibration syndrome. Br J Ind Med 1971; 28:90-3.

${ }^{6}$ Laitinen O, Nikkilä EA, Kivirikko KI. Hydroxyproline in the serum and urine. Acta Med Scand 1966;179:275-84.

7 Prockop DJ, Kivirikko KI. Relationship of hydroxyproline excretion in urine to collagen metabolism $A n n$ Intern Med 1967;66:1243-66.

${ }^{8}$ Emmrich R. Die Hydroxyprolinausscheidung im Harn bei chronischen Krankheiten des Bindegewebes. Z Gesamte Inn Med 1970;25:1062-5.

${ }^{9}$ Sroczyński J, Wegiel A, Mamczar A. Effects of vibration and noise on the excretion of glycosaminoglycans (mucopolysaccharides) and hydroxyproline. Med Pracy $1979 ; 30: 55-62$.

${ }^{10}$ Parekh AC, Jung DH. An improved method for determination of total hydroxyproline in urine. Biochem Med 1970;4:446-56.

11 Owen JA, Iggo B, Scandrett FJ, Stewart CP. The determination of creatinine in plasma or serum, and in urine; a critical examination. Biochem J 1954;58:426-37.

12 Schmidt RT, Toews JV. Grip strength as measured by the Jamar dynamometer. Arch Phys Med Rehabil 1970;51: 321-7.

${ }^{13}$ Prockop DJ, Sjoerdsma A. Significance of urinary hydroxyproline in man. J Clin Invest 1961;40:843-9.

${ }_{14}$ Ziff M, Kibrick A, Dresner E, Gribetz HJ. Excretion of hydroxyproline in patients with rheumatic and nonrheumatic diseases. J Clin Invest 1956;35:579-87.

${ }^{15}$ Howells GR, Wharton BA, McCance RA. Value of hydroxyproline indices in malnutrition. Lancet $1967 ; \mathrm{i}$ : 1082-3.

16 Younoszai MK, Kacic A, Dilling L, Haworth JC. Urinary hydroxyproline:creatinine ratio in normal term, preterm, and growth-retarded infants. Arch Dis Child 1969;44:517-20.

17 Allison DJ, Walker A, Smith QT. Urinary hydroxyproline: creatinine ratio of normal humans at various ages. Clin Chim Asta 1966;14:729-34.

$18 \mathrm{Gage} \mathrm{H}$. Correlation of segmental vibration with occupational disease. In: Wasserman DE, Taylor W, eds. 
Proceedings of the Second International Occupational Hand-Arm Vibration Conference Washington: National Institute for Occupational Safety and Health, 1977; 239-43.

${ }^{19}$ Kasamatsu T, Itoh N, Iwata $\mathrm{H}$. Biochemical changes in serum constituents in workers operating chain saws. Wakayama Medical Reports 1979;22:53-60.

${ }^{20}$ Kasamatsu T, Miyashita K, Shiomi S, Itoh N, Iwata H. Relationships among sarcoplasmic enzymes in serum, muscular strength and subjective symptoms in chain saw operators. Wakayama Medical Reports 1979;22: 95-102.

${ }^{21}$ Milano G, Gage $\mathbf{H}$, Wilson C. An investigation of occupational hand-arm vibration. Bull NY Acad Med 1977; 53:823-8.

${ }^{22}$ Matoba T, Kusumoto $\mathrm{H}$, Mizuki $\mathrm{Y}$, Kuwahara $\mathrm{H}$, Inanaga $\mathrm{K}$, Takamatsu $\mathrm{M}$. Clinical features and laboratory findings of vibration disease: A review of 300 cases. Tohoku J Exp Med 1977;123:57-65.

${ }^{23}$ Futatsuka M, Takamatsu M, Sakurai T, et al. Vibration hazards in forestry workers of the chain saw operators of a determinated area in Japan. Journal of Science of Labour 1980;56:27-48.

${ }^{24}$ Iwata H. Effects of rock drills on operators (part 3). Joint and muscle pain, and deformity of bone and joint. Ind Health 1968;6:47-58.

${ }^{25}$ Burke MJ, Fear EC, Wright V. Bone and joint changes in pneumatic drillers. Ann Rheum Dis 1977;36:276-9.

${ }^{26}$ Laitinen J, Puranen J, Vuorinen P. Vibration syndrome in lumbermen (working with chain saws). JOM 1974;16: 552-6.

${ }^{27}$ Bendz P. Systematization of the grip of the hand in relation to finger motor systems. Scand J Rehabil Med $1974 ; 6: 158-65$ 